\title{
Cryptic diversity in a fig wasp community- morphologically differentiated species are sympatric but cryptic species are parapatric
}

Article

Accepted Version

Darwell, C. T. and Cook, J. M. (2017) Cryptic diversity in a fig wasp community-morphologically differentiated species are sympatric but cryptic species are parapatric. Molecular Ecology, 26 (3). pp. 937-950. ISSN 1365-294X doi: https://doi.org/10.1111/mec.13985 Available at https://centaur.reading.ac.uk/69301/

It is advisable to refer to the publisher's version if you intend to cite from the work. See Guidance on citing.

Published version at: http://dx.doi.org/10.1111/mec. 13985

To link to this article DOI: http://dx.doi.org/10.1111/mec.13985

Publisher: Wiley

All outputs in CentAUR are protected by Intellectual Property Rights law, including copyright law. Copyright and IPR is retained by the creators or other copyright holders. Terms and conditions for use of this material are defined in the End User Agreement. 


\section{CentAUR}

Central Archive at the University of Reading

Reading's research outputs online 
1 Article title: Cryptic diversity in a fig wasp community - functionally differentiated species are

2 sympatric but cryptic species are allopatric

3

4 Authors:

5 Darwell, C.T., ${ }^{\mathrm{a}, \mathrm{b}}$ \& Cook, J.M.,.

$6 \quad{ }^{a}$ School of Biological Sciences, University of Reading, Reading RG6 6AS, UK.

7 b Okinawa Institute of Science and Technology, 1919-1 Tancha, Onna-son, Okinawa, 904-0495,

$8 \quad J a p a n ;$ email: ctdarwell@gmail.com

$9 \quad{ }^{\mathrm{c}}$ Hawkesbury Institute for the Environment, University of Western Sydney, Locked Bag 1797,

10 Penrith South DC, New South Wales 1797, Australia; email: james.cook@westernsydney.edu.au

11

12 Keywords: community assembly; niche theory; neutral theory; cryptic species; fig wasps; alpha

13 diversity; beta diversity

15 Corresponding author: Clive T. Darwell; Okinawa Institute of Science and Technology, 1919-1

16 Tancha, Onna-son, Okinawa, 904-0495, Japan; Tel: +81 (0)98 966 8866; email:

17 ctdarwell@gmail.com; Fax: +81 (0)989823420

19 Running title: Cryptic diversity predicts species coexistence 
21 Abstract

22 A key debate in ecology centres on the relative importance of niche and neutral processes in

23 determining patterns of community assembly with particular focus on whether ecologically

24 similar species with similar functional traits are able to coexist. Meanwhile, molecular studies are

25 increasingly revealing morphologically indistinguishable cryptic species with presumably similar

26 ecological roles. Determining the geographic distribution of such cryptic species provides

27 opportunities to contrast predictions of niche versus neutral models. Discovery of sympatric

28 cryptic species increases alpha diversity and supports neutral models, while documentation of

29 allopatric/parapatric cryptic species increases beta diversity and supports niche models. We tested

30 these predictions using morphological and molecular data, coupled with environmental niche

31 modelling analyses, of a fig wasp community along its $2700 \mathrm{~km}$ latitudinal range. Molecular

32 methods increased previous species diversity estimates from eight to eleven species, revealing

33 morphologically cryptic species in each of the four wasp genera studied. Congeneric species pairs

34 that were differentiated by a key morphological functional trait (ovipositor length) coexisted

35 sympatrically over large areas. In contrast, morphologically similar species, with similar

36 ovipositor lengths, typically showed parapatric ranges with very little overlap. Despite parapatric

37 ranges, environmental niche models of cryptic congeneric pairs indicate large regions of potential

38 sympatry, suggesting that competitive process are important in determining the distributions of

39 ecologically similar species. Niche processes appear to structure this insect community and

40 cryptic diversity may typically contribute mostly to beta rather than alpha diversity. 
43 Ecologists have long sought to explain patterns of biodiversity and community assembly. A

44 prominent recent debate has centred on the relative importance of 'neutral' (Hubbell 2001) versus

45 'niche' (e.g. Chesson 2000, Chase and Leibold 2003) processes that influence both species

46 diversification and coexistence (e.g. Matthews and Whittaker 2014). In neutral models, observed

47 patterns of species abundance and coexistence are stochastic outcomes unlinked to ecological

48 functional traits. In contrast, diversity under niche models results from competitive and adaptive

49 processes that lead to more stable patterns of community assembly. Importantly, niche models

50 predict that localised coexistence of competing species should be limited by their ecological

51 similarity (Macarthur and Levins 1967), while neutral models do not, providing us with testable

52 alternative hypotheses.

53 Over the last 10-15 years, molecular investigation of biodiversity has increased rapidly

54 and revealed extensive cryptic species diversity (Kress et al. 2015). Cryptic species exist when

55 several reproductively isolated groups are genetically distinguishable within a single formally

56 described species, or undescribed but recognisable "morphospecies". Such cryptic species are

57 likely to be ecologically very similar, due to lack of divergence in morphological functional traits

58 and close relatedness. Consequently, cryptic species should coexist often in sympatry if neutral

59 community assembly predominates, but rarely if niche processes are more important. This

60 provides an excellent framework in which to test neutral versus niche processes. To date, we

61 know little about how cryptic diversity is structured locally and distributed geographically.

63 competitively exclude each other. For example, Voda et al. (2015) found that pairs of cryptic 
64 butterfly species in the western Mediterranean are less likely to co-occur than non-cryptic 65 congeners, suggesting that ecological similarity limits local coexistence. Similarly, DNA 66 barcoding showed that morphospecies of rolled-leaf beetles consist of species-complexes 67 adjacently distributed along altitudinal gradients (Garcia-Robledo et al. 2016). However, neither study specifically investigated whether the identified cryptic species display any functional trait

69 divergence or have ecologically diversified according to resource requirements. Furthermore, identifying non-sympatric distributions of ecologically similar species does not necessarily indicate that niche processes are determining patterns of co-existence. For

72 example, it is believed that the majority of speciation events are not driven by niche divergence

73 but rather by genetic differentiation between geographically isolated allopatric populations

74 (Coyne and Orr 2004), often followed by secondary contact that might leave sister species cooccurring in sympatry (e.g. Pigot et al. 2016). However, specific conditions have been proposed

76 that should be typically viewed as supporting a hypothesis of competitive exclusion among 77 ecologically similar, closely related species (Anderson et al. 2002, Gutierrez et al. 2014). These

78 include focal species showing parapatric ranges with narrow contact zones, and the use of 79 ecological niche models (ENMs) to identify regions of potential sympatry coupled with numerical inequities in species abundance across identified regions (Anderson et al. 2002,

81 Darwell et al. 2016).

Testing whether pairs/sets of cryptic species are typically sympatric or allopatric also has

83 important implications for food web structure. Sympatric cryptic species contribute noise to our 84 understanding of ecological food webs. For example, some recent studies have found that one 85 supposed resource-generalist species actually comprises multiple resource-specialist cryptic 86 species (Hebert et al. 2004, Smith et al. 2007). Meanwhile, at a community level, Smith et al. 
87 (2011) found that DNA barcoding of the 100+ arthropod enemies of the spruce budworm not only increased measures of species richness but also reduced estimates of food web connectance

89 (May 1973). However, studies highlighting coexisting cryptic species often focus on only one or 90 a few neighbouring sites (e.g. Molbo et al. 2003, Wellborn and Cothran 2004, Montero-Pau and

91 Serra 2011, Smith et al. 2011) and local patterns may not be representative of interactions across 92 species' geographic ranges.

The implications of cryptic species coexistence patterns also ramify to the

94 macroecological level of regional biodiversity patterns. Essentially, sympatric cryptic species

95 contribute to local diversity ('alpha diversity’ - sensu Whittaker 1972), but allopatric (or

96 parapatric) cryptic species contribute to geographic diversity across sites ('beta diversity’).

97 Testing for these alternative patterns helps to evaluate total ('gamma') diversity and clarifies which species actually interact at a local scale. This is key to understanding the interplay between

99 biodiversity and ecological function, as well as the ecological and coevolutionary dynamics of 100 species interactions (Paine 2002, Duffy et al. 2007, Smith et al. 2011, Rooney and McCann 101 2012).

Exploring these issues first requires correct delimitation of species (Cristescu 2014),

103 which is difficult for many invertebrates, because diversity is high and many species are 104 undescribed. In addition, intraspecific phenotypic variation can be very high (Cook et al. 1997, 105 Xiao et al. 2010, Puniamoorthy et al. 2012) and cryptic species further complicate the situation. 106 Consequently, investigations of insect community ecology and biodiversity increasingly 107 recognise the need to include barcoding and/or related molecular techniques alongside morphological and ecological data (Blaxter 2003, Hebert et al. 2003, Hebert and Gregory 2005, 109 Acs et al. 2010). This is certainly true for communities of insect herbivores and their associated 
parasitoid enemies that constitute perhaps $20 \%$ of global species diversity (Price 1980, May 1990).

The multitrophic insect communities hosted by Ficus (Moraceae) fruits (figs) are a

113 valuable emerging model for studies of insect community ecology and evolution (e.g. Hawkins and Compton 1992, Kerdelhue et al. 2000, Xiao et al. 2010, Segar et al. 2013, Segar et al. 2014).

115 Ficus is a globally distributed, largely tropical, plant genus of $>750$ species, famous for its classic mutualism with fig- pollinating wasps (Chalcidoidea: Agaonidae). However, most of the insect 117 species are non-pollinating fig wasps (NPFW) and either gall fig tissue (hereafter "gallers") or 118 parasitise other wasp larvae (hereafter "parasitoids"). These fig wasp communities are restricted 119 to the well-defined resource of the fig fruit, involve insects that are almost all specific to a single 120 Ficus species, and are therefore geographically defined by the range of the host plant.

The several thousand species of fig wasps globally belong to diverse chalcid wasp

122 lineages (Rasplus et al. 1998, Cook and West 2005), but can be categorised into five functional 123 groups (Segar et al. 2014): pollinators; small and large gallers; and small and large parasitoids. At 124 the level of individual insects, pollinators are typically more common than non-pollinators, while 125 gallers and parasitoids typically far outnumber large ones (Segar et al. 2014). Within these 126 communities, ovipositor length is a key functional trait as it mediates the ability to lay eggs in 127 resources (seeds or insect larvae) in different fig tissue layers (al-Beidh et al. 2012), or in figs at 128 different stages of growth. In other words, ovipositor length is a key axis for niche differentiation 129 (Weiblen and Bush 2002, Proffit et al. 2007, Segar et al. 2013). As fig wasps show very high host 130 plant specificity, communities on different fig species are largely independent (Cook and Segar 131 2010), although some notable exceptions occur (McLeish et al. 2010, McLeish and van Noort 132 2012). However, cryptic pollinator (Molbo et al. 2003, Haine et al. 2006, Darwell et al. 2014) and 
133 non-pollinator species (Bouteiller-Reuter et al. 2009, Zhou et al. 2012) have been reported

134 recently and widespread fig wasp communities provide opportunities to test the impact of cryptic

135 species on community ecology and biodiversity patterns.

136 Here, we focus on two fig wasp functional groups (small gallers and parasitoids) hosted

137 by a single fig species (Ficus rubiginosa) with a wide latitudinal range. Wasps in these functional

138 groups comprise $85 \%$ of all non-pollinator wasps developing in F. rubiginosa figs (Segar et al.

139 2014), so are both ecologically important and amenable to dense sampling. In addition, they have

140 long external ovipositors - a key functional trait that can be measured and used to assess

141 ecological divergence (e.g. Weiblen \& Bush 2002). Our specific aims are to:

142 1) Use wide geographic sampling, combined with morphological and molecular taxonomy to 143 establish the number of small galler and parasitoid wasp species hosted by F. rubiginosa.

144 2) Test if cryptic species that do not differ in key functional traits (ovipositor length and body

145 size) are largely sympatric, representing hidden alpha diversity, or allopatric/parapatric (replacing 146 each other across geographic sites), representing hidden beta diversity.

147 3) Test if closely related (congeneric) species that do differ in these key functional traits coexist 148 locally or show geographical replacement.

149 4) Use ENMs to determine the geographic extent of potential sympatry for focal species pairs of 150 interest. 
153

\section{Methods}

Study system

The endemic Australian fig, Ficus rubiginosa, occupies a ca. $3000 \mathrm{~km}$ coastal belt that stretches from northern Queensland (tropical) to southern New South Wales (Mediterranean climate) in diverse habitats including eucalypt scrub, vine thicket and rainforest (Dixon et al. 2001). In addition to its five genetically delimited pollinator species (Darwell et al. 2014), morphological and molecular investigation has identified at least 15 NPFW species, comprising 11 genera from six families and subfamilies (Segar et al. 2014). The small galler and small parasitoid functional groups comprise species from four genera: Sycoscapter, Philotrypesis, Watshamiella (all Sycoryctinae) and Eukobelea (Sycophaginae). For the three sycoryctine genera, different ecological niches can be inferred. Sycoscapter (parasitoids) and Philotrypesis (inquilines) appear to be ecologically differentiated according to host attack strategy (Tzeng et al. 2008, Zhai et al. 2008). Meanwhile, some Watshamiella species have been shown to be hyperparasitic, reliant on other parasitoid wasp taxa to pierce fig fruit walls in order to gain oviposition access (Compton et al. 2009). Finally, the sycophagine Eukobelea is thought to be a flower galler and as such should not compete directly with sycoryctine parasitoids (Segar et al. 2014). In three of the four genera, there are distinct morphospecies that differ substantially in either ovipositor length (Sycoscapter and Watshamiella) or colour (yellow and black Philotrypesis) (Segar et al. 2014). Philotrypesis morphospecies may be ecologically differentiated as some yellow (non-pigmented) fig wasps are known to disperse nocturnally (Warren et al. 2010). Further, in Sycoscapter there are two genetically described cryptic species within the "short" morphospecies (Bouteiller-Reuter et al. 2009). 


\section{Field sampling}

Most sampling was conducted in Queensland during Apr-Sep 2009 along the eastern seaboard between Brisbane $\left(26^{\circ} 46 \mathrm{~S}, 153^{\circ} 02 \mathrm{E}\right)$ and Dimbulah $\left(17^{\circ} 01 \mathrm{~S}, 145^{\circ} 19 \mathrm{E}\right)$ in the Atherton Tablelands. Some inland sampling was carried out around Forty Mile Scrub (18 06S, $\left.144^{\circ} 49 \mathrm{E}\right)$ and Chillagoe (17 $\left.10 \mathrm{~S}, 144^{\circ} 31 \mathrm{E}\right)$. Other sampling occurred in the Townsville and Brisbane regions in 2007-8, while sampling in New South Wales (NSW) has been conducted sporadically before 2008 and also in 2012-14.

For all taxa, we attempted to sample individuals from many sites across the host plant range and include only one individual per morphospecies per fig in our analyses. Overall, samples were taken from $>500$ fig syconia from 166 sites. Near-ripe figs were placed into hatching jars with mesh lids that allowed air flow, while preventing overheating and wasp escape. After $48 \mathrm{~h}$ each fig and all its exited wasps were placed into 70\% ethanol. Alternatively, figs were placed directly into alcohol and wasps were dissected out at a later date.

\section{Molecular methods}

We extracted DNA using a Chelex method (West et al. 1998) and then amplified one mitochondrial (cytb) and one nuclear (ITS2) marker. mtDNA is employed regularly in animal molecular species delimitation (e.g. barcoding), and nuclear ITS2 provides a complementary nuclear marker for species delimitation in Hymenoptera (Xiao et al. 2010). Sample sizes used for molecular analyses are detailed in Table 2. Sequencing was conducted on individuals from across the entire host plant range (see supplementary information for further details).

We first attempted to sequence all wasps using the CP1-CB2 cytb primer set (CP1 - GAT GAT GAA ATT TTG GAT C and CB2 - ATT ACA CCT CCT AAT TTA TTA GGA AT; Harry 
et al. 1998), which amplifies a fragment of about $600 \mathrm{bp}$. However, this did not amplify all taxa, and so the shorter (ca. $400 \mathrm{bp}$ ) CB1-CB2 fragment was employed for these species (CB1 - TAT GTA CTA CCA TGA GGA CAA ATA TC; Jermiin and Crozier 1994). The nuclear internal transcriber spacer 2 (ITS2) region was sequenced for all taxa using the primers ITS2F (ATT CCC GGA CCA CGC CTG GCT GA) and ITS2R (TCC TCC GCT TAT TGA TAT GC) (ITS2F ATT CCC GGA CCA CGC CTG GCT GA and ITS2R - TCC TCC GCT TAT TGA TAT GC; White et al. 1990).

PCR amplification was conducted using a Techne Touchgene gradient machine with the following conditions: 1) $\mathrm{CP} 1-\mathrm{CB} 2: 3 \mathrm{~min}$ at $94^{\circ} \mathrm{C}, 40$ cycles of $30 \mathrm{~s}$ at $92^{\circ} \mathrm{C}, 60 \mathrm{~s}$ at $48^{\circ} \mathrm{C}, 1 \mathrm{~min}$ 30s at $72^{\circ} \mathrm{C}$, and $10 \mathrm{~min}$ at $\left.72^{\circ} \mathrm{C} .2\right) \mathrm{CB} 1-\mathrm{CB} 2: 3 \mathrm{~min}$ at $94^{\circ} \mathrm{C}, 30$ cycles of $15 \mathrm{~s}$ at $95^{\circ} \mathrm{C}, 20 \mathrm{~s}$ at $45^{\circ} \mathrm{C}, 30 \mathrm{~s}$ at $72^{\circ} \mathrm{C}$, and $10 \mathrm{~min}$ at $72^{\circ} \mathrm{C}$. 3) ITS2: $5 \mathrm{~min}$ at $94^{\circ} \mathrm{C}, 35$ cycles of $30 \mathrm{~s}$ at $94^{\circ} \mathrm{C}, 40 \mathrm{~s}$ at $55^{\circ} \mathrm{C}, 40 \mathrm{~s}$ at $72^{\circ} \mathrm{C}$, and $10 \mathrm{~min}$ at $72^{\circ} \mathrm{C}$. Subsequent ethanol purification and sequencing, by BigDyeTM terminator cycling and a 3730xl DNA analyser, were conducted by Macrogen Inc.

\section{Sequence data analysis}

Chromatogram quality was assessed using Finch TV Version 1.4.0 and sequences edited and aligned using BioEdit (Hall 1999) with final adjustments by eye. Bayesian methods were used to construct phylogenies using MrBayes (Ronquist and Huelsenbeck 2003), after choosing the best model of nucleotide substitution for each gene with MrModeltest in PAUP* (Swofford 2002). Log-likelihood ratio tests selected the GTR $+\mathrm{I}+\mathrm{G}$ model for both the nuclear and mtDNA datasets. ITS2 sequences were trimmed at either end because it is difficult to identify sequence start and end points due to the presence of indels (e.g. Li et al. 2010, Xiao et al. 2010). 
Species were delimited as clearly defined congruent clades (with $\geq 0.95$ p-values for at

221 least one marker) from separate cytb and ITS2 phylogenies using the phylogenetic species

222 concept (PSC; Eldredge and Cracraft 1980). To corroborate PSC species delimitation we

223 investigated cytb data with jMOTU software (Jones et al. 2011). This software produces a

224 frequency distribution of pairwise genetic distances, and an inflection point in this distribution

225 represents the "barcoding gap" between species, and thus identifies molecular operational

226 taxonomic units (MOTUs). Assessment of pairwise Kimura-2-parameter (K2P; Kimura 1980)

227 genetic distances between putative congeneric species was performed to further investigate PSC

228 delimitation. For Philotrypesis 'yellow', sequencing of cytb in many individuals revealed two

229 species. However, within each species there was almost no sequence variation, so only a few

230 individuals were sequenced for ITS2, which supported cytb analyses by revealing two species.

Morphological analyses

We used ANCOVA to explore morphological differentiation between genetically

234 delimited congeneric species focusing on two key functional traits - ovipositor length, which

235 determines at what stage or what depth a wasp may lay eggs into the fig, and body size (using

236 hind tibia length as an index). We refer to the ratio between these two traits as "relative

237 ovipositor length" (ROL). These analyses were performed in R (R Core Team 2015). For further

238 comparison of pairs of congeneric species, we also calculated a "disimilarity index", where DI =

$239\left(\mathrm{ROL}_{\mathrm{A}}-\mathrm{ROL}_{\mathrm{B}}\right) / \mathrm{ROL}_{\mathrm{A}}$ between species A with the higher ROL and congeneric species $\mathrm{B}$ with

240 the lower ROL. 
To evaluate signatures of competitive exclusion and identify regions of potential

245 sympatry we filtered locality data for each molecularly delimited species to include the maximum 246 number of locations that were at least $10 \mathrm{~km}$ apart (Anderson and Raza 2010, Boria et al. 2014).

247 This reduces sampling biases from non-uniform sampling efforts. For environmental data, we 248 used the 19 WorldClim bioclimatic variables at 30 " resolution $\left(=0.86 \mathrm{~km}^{2}\right.$ pixels) (Hijmans et al. 249 2005; <http://biogeo.berkeley.edu/worldclim/worldclim.htm >). The WorldClim data are derived 250 from precipitation, temperature and seasonality records and are a standard dataset for baseline 251 predictions of species' geographic distributions.

We used Maxent version 3.3.3k which uses the maximum entropy algorithm to calculate 253 ENMs (Phillips et al. 2006, Phillips and Dudik 2008). To ensure the correct model was fitted and 254 avoid model overfitting, we used the 'ENMeval' package (Muscarella et al. 2014) in R (R 255 development team) to determine the optimal feature class (FC) and regularisation multiplier 256 (RM) settings. FC and RM settings were obtained by choosing the settings that returned a $\triangle \mathrm{AICc}$ 257 score of zero (Muscarella et al. 2014). For each species, models were evaluated using only 258 environmental data from the subject species' range by creating a mask variable delimited by the 259 'minimum convex polygon' around all species' locations and a $0.5^{\circ}$ buffer zone in the R package 260 adehabitatHR (Calenge 2006). To partition occurrence localities into testing and training bins 261 (folds) for $k$-fold cross-validation, we used the 'checkerboard1' option for species with greater 262 than 25 localities (i.e. $>10 \mathrm{~km}$ apart) and the 'jackknife' option for species with between 15-25 263 localities (Muscarella et al. 2014). Additionally, the 'ENMeval' package struggles to evaluate 264 optimal models for species with less than 15 locality records (here Sycoscapter 'short' southern 
species; Philotrypesis ‘yellow' species 1; Philotrypesis 'black' southern species; Eukobelea both species); for these species we used the default settings in Maxent (under these circumstances it is

267 likely that the ENM models are over-fitted and therefore represent conservative estimates of 268 species' potential ranges; Muscarella et al. 2014). ENMs across the entire study region were run 269 in Maxent with a 10\% training threshold rule which rejects the lowest $10 \%$ of predicted values

270 (Pearson et al. 2007). This allows the transformation of probabilistic ENMs into binary

271 predictions of suitable vs. non-suitable climatic conditions at each pixel. These ENMs were then 272 overlaid for particular species pairs of interest.

\section{$274 \quad$ Results}

275 Sequencing results

Sequences were obtained from 307 and 194 individuals for cytb and ITS2, respectively.

277 We found no evidence of pseudogenes or heteroplasmy (see Table 1; Supplementary Information 278 for further details). According to our species delimitations, mitochondrial K2P pairwise distances 279 range from $0-7.24 \%$ within species and $2.75-16.00 \%$ between different species in the same 280 genus. The corresponding values for ITS2 data are $0-11.25 \%$ and $0.93-48.90 \%$ respectively. The high ITS2 values reflect large indels that contribute greatly to distances between species, whereas 282 the aligned nucleotide regions of these species are far less divergent. parasitoid species associated with Ficus rubiginosa. The previous figure was eight species and 
our analysis adds three cryptic species in the genera Philotrypesis and Eukobelea (Table 2). All individuals sequenced for both genes were unambiguously placed into congruent cytb and ITS2 clades (Figure S1) and node support values for all posited species were high ( $\mathrm{p} \geq 0.95)$ for at least one marker. Similarly, PSC species delimitation was congruent with MOTU identification for cytb data (Figure S2). The congruence of results across nuclear and mtDNA markers for all individuals sequenced supports reproductive isolation of our identified species and provides no evidence for hybridisation. Critically, this includes all sympatric congeneric individuals from different species. In addition, where we recognise congeneric morphospecies (e.g. Watshamiella 'long' and 'short') that differ in functional traits, these morphospecies are also congruent with molecular species divisions (see below).

\section{Relationships between sympatric co-occurrence and degree of morphological similarity}

Sympatric congeneric species (i.e. Sycoscapter 'long' and 'short', two Philotrypesis 'yellow' and Watshamiella 'long' and 'short'; Figure 1, Table 3) generally have significantly different ROLs; i.e. they are functionally differentiated. In contrast, congeneric species with ROLs described by the same simple regression model are essentially parapatric. Consequently, dissimilarity indices (DI) are consistently higher for congeneric species that are sympatric $(0.190-$ $0.327)$ and lower (0.005-0.072) for those that are allopatric (Table 3).

There are also some more nuanced aspects of these patterns, but these do not compromise the strong general patterns. First, both the Sycoscapter 'short' and Eukobelea congeneric pairs occupy largely parapatric northern and southern ranges, but have small contact zones around Brisbane in the centre of the host plant range. In addition, the 'southern' species of each pair also has a disjunct small northern refuge at Forty Mile Scrub. Also, the two virtually parapatric 
310 Philotrypesis 'black' species (one 'northern' individual was found in New South Wales - figure

311 1d) actually have significantly differentiated ROLs. However, their DI (0.072) is still very low,

312 suggesting little functional differentiation compared to widespread sympatric pairs that have DI

$313>0.19$. Typically, ovipositor length in congeneric pairs with statistically differentiated ROLs is

$314 \sim 1 \mathrm{~mm}$ compared to $\sim 0.1 \mathrm{~mm}$ in Philotrypesis 'black' (Figure 1d; indicating that the

315 discriminative statistical power of the ANCOVA test is high).

317 Species distribution models

318 For morphologically indistinguishable (i.e. cryptic) congeneric species pairs, SDMs

319 typically show large regions of potential sympatry indicated by overlapping models (Figure 1).

320 For Sycoscapter 'short' (Figure 1b), the 'southern' species is predicted to be climatically adapted

321 to the entire east coast of Australia including the extensive regions of Queensland where it is not

322 found. For Philotrypesis 'black' (Figure 1d), the 'northern' species is expected to be found across

323 the entirety of the east coast including the southern regions where it is typically excluded. For

324 Eukobelea (Figure 1f), 'the southern' species appears climatically adapted to the entire east coast

325 including the northern regions from which it is excluded. Finally, for morphologically

326 distinguishable, sympatric congeners, ENMs predict wide-ranging regions of species overlap

327 (Figures 1a,c,e). In summary, ENM analyses show that the ranges of cryptic species are far

328 smaller than expected based on abiotic factors, suggesting a major role for biotic interactions. 


\section{Discussion}

332 As molecular investigation into the scale and structure of global biodiversity continues we will

333 begin to form a more nuanced picture of the patterns and ecological significance of cryptic

334 diversity (Smith et al. 2007, Smith et al. 2011). A fundamental issue is to understand the major

335 processes that determine community assembly and the geographic relationships between pairs of

336 cryptic species can provide important evidence on the relative impact of niche versus neutral

337 processes in community assembly. In particular, we can test if ecologically similar cryptic species

338 coexist or exclude each other at community and geographic scales (e.g.Voda et al. 2015). Our

339 study of a multitrophic insect community that harbours extensive cryptic diversity offers a

340 comprehensive view of a complex community across a wide geographic range and uses the

341 uncovered diversity to test the key predictions about coexistence.

Cryptic species, functional trait divergence and local coexistence

Our molecular species delimitation strongly supports the existence of two small galler and

345 nine small parasitoid species. This is a marked increase over a previous estimate of eight species

346 in total, which already recognised two cryptic species in Sycoscapter (Segar et al. 2014). It also

347 means that all four genera are now known to include morphologically similar but genetically

348 distinct species, emphasising that cryptic diversity is a significant component of total diversity.

Niche theory posits that competing species should only coexist locally in sympatry if they

350 diverge along some ecological trait axes or exhibit differential responses to one or more of

351 resource availability, temporal or spatial heterogeneity, or predation. In contrast, neutral models

352 predict communities that are assembled more stochastically and that ecologically similar species 
353 will often coexist. Within three (Sycoscapter, Philotrypesis and Watshamiella) of our four study

354 genera we found co-occurring species with marked differences in a key functional trait -

355 ovipositor length (Figure 1a,c,e). This correlates with niche differentiation because wasps with

356 different ovipositor lengths can lay eggs into different tissue layers of in figs or at different stages

357 of fig development (Proffit et al. 2007, Segar et al. 2014).

358 In contrast, cryptic congeneric species that lack this (or other obvious) trait divergence

359 tend not to coexist locally and, though widely distributed, are predominantly allopatric (Figure

3601 1b,d,f). For example, the two Sycoscapter 'short' species, Philotrypesis 'black' and Eukobelea

361 each comprise two species clearly identified by molecular taxonomy, but with low DIs and no or

362 only subtle differences in ROLs. In Philotrypesis 'black', ANCOVA analyses statistically

363 distinguished the species-specific ROLs; however, the low DI coupled with a visual inspection of

364 data showing overlapping clouds of points suggests that their ROLs represent functionally similar

365 ecological roles. For these three species pairs, the lack of differentiated ROLs and DIs suggest

366 similar attack strategies on figs that, through limiting similarity, would hinder local coexistence.

367 In the case of Philotrypesis "yellow" there is some nuance to the overall picture. Although

368 both species co-occur widely in Queensland, species 1 appears absent from southern Queensland

369 and northern NSW. However, this could potentially be a sampling artefact as collection effort

370 was not as intense in these regions. Moreover, we have only found a small number of

371 Philotrypesis 'yellow' wasps in the furthest north parts of New South Wales (Figure 1c),

372 suggesting that these yellow species are predominantly tropical and do not extend to the higher

373 latitudes of southern NSW. We also note that the intermediate sympatry/allopatry of the two

374 Philotrypesis 'yellow' mirrors their intermediate dissimilarity indices (DI) that lie between the

375 two extremes for allopatric and sympatric congeneric pairs. 
Ecological processes determining species coexistence

Although the allopatric/parapatric geographic distributions of our cryptic congeneric

379 NPFW species support a hypothesis of limiting similarity hindering local coexistence, these 380 patterns are also consistent with a model of allopatric speciation with subsequent secondary 381 contact (Coyne and Orr 2004). However, as these species' northern and southern ranges typically 382 display narrow contact zones around Brisbane (excluding a single incursion into southern regions 383 by a 'northern' Philotrypesis 'black' individual and the consistently anomalous Forty Mile Scrub 384 region - see later Discussion), the latter hypothesis rests on the supposition that we are viewing 385 the point in evolutionary history when these cryptic pairs, unlike the morphologically 386 distinguishable congeners in this community, are undergoing secondary reconnection before 387 developing more sympatric ranges. These patterns, along with our ENMs indicating large areas of 388 potential sympatry with one of a pair of species largely absent, fulfil the required conditions proposed by Anderson et al (2002) to indicate competitive exclusion among ecologically similar, 390 closely related species. Moreover, recent findings from this community showing that Sycoscapter 391 'long' forms a single unbroken population across the range of $F$. rubiginosa (Sutton et al. 2016) 392 suggests that the geographic ranges of these NPFWs are most likely determined by adaptive or 393 competitive processes rather than being the result of sedentary range expansion. Additionally, 394 although patterns of allopatric speciation followed by secondary contact may be common (e.g. 395 Pigot et al. 2016), such studies do not typically test whether secondarily coexisting species are in 396 direct competition for resources. For the small NPFW community occupying F. rubiginosa, we 397 can confidently infer that all species are restricted to targeting the uniform resources entombed in 398 the fig syconium as recent work indicates these species are all host specific (Darwell 2013). 
Do cryptic species increase alpha or beta diversity?

Our findings suggest that detection of cryptic species increases beta diversity (geographic turnover of species) with little effect on alpha diversity in any given site or region. This implies

403 that local alpha diversity may change little across the host plant range, but more detailed

404 quantitative studies are needed to test this hypothesis. If the link between cryptic and beta

405 diversity proves general across other taxa, features such as local food web dynamics and

406 ecological functioning and stability (Rooney and McCann 2012) may be similar across ranges

407 despite considerable cryptic diversity. Assessing patterns of beta diversity is a key research area

408 in ecology (e.g. Graham and Fine 2008) and we show here the need to combine comprehensive

409 geographic sampling with molecular revelation of cryptic species to reveal true biodiversity

410 patterns. Moreover, our findings that functionally equivalent congeneric species do not typically

411 co-occur suggests that niche-based models of community assembly better explain species

412 coexistence among the small NPFWs of $F$. rubiginosa compared to predictions originating from 413 neutral theory (Hubbell 2001).

The importance of widespread geographic sampling

Although some empirical studies (Molbo et al. 2003, Wellborn and Cothran 2004,

417 Montero-Pau and Serra 2011) suggest that ecologically similar cryptic species may coexist, 418 extrapolation from studies with limited geographic sampling is risky. For example, in both 419 Sycoscapter 'short' and Eukobelea, two cryptic species co-occur around Brisbane. Indeed, this is 420 where the two cryptic Sycoscapter 'short' species were first detected (Bouteiller-Reuter et al. 421 2009) in a single population and at similar frequencies (Cook et al. 2015). We might therefore 
422 predict that they co-occur widely. However, the Brisbane region represents a tiny fraction of their

423 overall ranges (as revealed by this study) and our comprehensive sampling reveals a northern and

424 a southern species that are widely parapatric but have a narrow overlap zone in the middle of the

425 host plant range. This could be a case of allopatric speciation with limited secondary contact

426 following range expansion. As such, one species may eventually outcompete the other in this

427 zone or localised coexistence may continue as competitive exclusion is never realised due to

428 ongoing immigration from neighbouring populations (e.g. Darwell et al. 2014). A recent

429 population genetic study showed that Sycoscapter 'long' is effectively one large population

430 throughout the host plant range, with only weak isolation-by-distance (Sutton et al. 2016). This

431 suggests substantial dispersal and wide gene flow in at least some Sycoscapter wasps, as also

432 reported for many fig-pollinating wasps, which would impede the formation of allopatric species

433 pairs on the same host plant.

434 Similar north-south clinal patterns of cryptic diversification have been noted in the 435 pollinators of F. rubiginosa (Darwell et al. 2014). The Burdekin gap, located just south of

436 Townsville, is a well-documented major biogeographical barrier (Joseph and Moritz 1994). In

437 fig-wasps, one of the pollinator species associated with F. rubiginosa is found almost exclusively

438 around Townsville, whilst this study support a similar scenario for one of the yellow

439 Philotrypesis species. This region has been noted as a transitional zone for species displacement

440 in Drosophila (Schiffer et al. 2004, van Heerwaarden et al. 2009). The McPherson range around

441 Brisbane is another recognised major biogeographical barrier (Edwards and Melville 2010), and

442 Sycoscapter 'short', Philotrypesis 'black' and Eukobelea seem to divide here. At a gross level

443 this Queensland-NSW split equates to a tropical-Mediterranean biome division straddling the 444 geographic range of this fig species and may explain many species' boundaries in this study. Of 
445 further intrigue is that the north-south split in Sycoscapter 'short' and Eukobelea is not absolute.

446 In both genera, the 'southern' species also occurs at one site (Forty Mile Scrub) in inland

447 northern Queensland; a single 'southern' Sycoscapter was also found nearby ( 100km away) in

448 the Atherton Tablelands. The habitat at Forty Mile Scrub is remnant vine thicket, which was

449 previously widespread and is distinctive from the eucalypt scrub habitat where the other samples

450 were collected. Furthermore, the F. rubiginosa trees there are hemiepiphytic 'stranglers' rather

451 than the more common lithophytic rock-dwelling forms, and have notably larger figs (CTD, pers.

$452 o b$.). Thus, Forty Mile Scrub may favour otherwise southern-adapted species due to idiosyncratic

453 ecological circumstances and adds to the overall impression that alpha and beta diversity patterns

454 for small NPFWs inhabiting $F$. rubiginosa are driven by adaptive responses to a variety of

455 ecological and climatic factors which together support a dominant role for niche processes in

456 determining community assembly.

457 
Table 1. Summary characteristics of cytb and ITS2 sequence data. Pairwise intraspecific and interspecific distances are given using Kimura's two parameter algorithm (K2P). Sequence length is given in nucleotide base pairs.

\begin{tabular}{lcccccc}
\hline & \multicolumn{3}{c}{ cytb } & \multicolumn{3}{c}{ ITS2 } \\
\hline Genus & $\begin{array}{c}\text { Intraspecific } \\
\text { K2P (\%) }\end{array}$ & $\begin{array}{c}\text { Interspecific } \\
\text { K2P (\%) }\end{array}$ & $\begin{array}{c}\text { Sequence } \\
\text { length }\end{array}$ & $\begin{array}{c}\text { Intraspecific } \\
\text { K2P }(\%)\end{array}$ & $\begin{array}{c}\text { Interspecific } \\
\text { K2P }(\%)\end{array}$ & $\begin{array}{c}\text { Sequence } \\
\text { length }\end{array}$ \\
\hline Sycoscapter & $0-4.13$ & $6.25-14.29$ & 351 & $0-4.63$ & $2.58-8.66$ & $303-380$ \\
Philotrypesis & $0-7.24$ & $2.75-16.00$ & 394 & $0-6.67$ & $2.24-12.78$ & $320-358$ \\
Watshamiella & $0-2.06$ & $4.03-7.77$ & 692 & $0-3.73$ & $0.93-5.67$ & $300-348$ \\
Eukobelea & $0-3.93$ & $6.96-10.12$ & 663 & $0-11.25$ & $21.44-48.90$ & $520-565$ \\
\hline
\end{tabular}

Table 2. Species diversity estimates for small non-pollinating chalcid wasp taxa associated with $F$. rubiginosa as discriminated by molecular phylogenetic methods before and after current study. Known morphologically determinant characters indicated in parentheses (s-short ovipositor, 1-long ovipositor, y-yellow, b-black; §-congeneric species distinguishable by ovipositor-hind tibia allometry); Sample sizes shown for each delimited species.

\begin{tabular}{lccc}
\hline Wasp taxon & Previous findings & Current data & Sample size (N) \\
\hline Sycoscapter & $3(\mathrm{~s}, \mathrm{~s}, 1 \S)$ & $3(\mathrm{~s}, \mathrm{~s}, 1 \S)$ & $31,32,17$ \\
Philotrypesis & $2(\mathrm{y}, \mathrm{b})$ & $4(\mathrm{y} \S, \mathrm{y} \S, \mathrm{b}, \mathrm{b})$ & $44,77,21,15$ \\
Watshamiella & $2(\mathrm{~s} \S, 1 \S)$ & $2(\mathrm{~s} \S, 1 \S)$ & 27,46 \\
Eukobelea & 1 & 2 & 25,23 \\
\hline Total & $\mathbf{8}$ & $\mathbf{1 1}$ & $\mathbf{3 6 0}$ \\
\hline
\end{tabular}

Table 3. ANCOVA results, dissimilarity indices and relationship to congeneric co-occurrence in small NPFW species found on $\boldsymbol{F}$. rubiginosa. ANCOVA: the minimum adequate model method of Crawley (2007) is employed; ov tib indicates a model with no factorial parameters; ov tib+spp indicates a model with separate intercepts and a single slope; ov tib*spp indicates a model with separate intercepts and slopes. P-values indicate statistical support of the favoured model over the hierarchically simpler model. Dissimilarity indices range between 0.005-0.072 for allopatric species pairs and $0.190-0.327$ for species pairs found in sympatry. See figure 1 for ANCOVA plots.

\begin{tabular}{|c|c|c|c|c|c|c|}
\hline & $\begin{array}{c}\text { Sycoscapter } \\
\text { long and short }\end{array}$ & $\begin{array}{c}\text { Sycoscapter } \\
\text { short }\end{array}$ & $\begin{array}{c}\begin{array}{c}\text { Philotrypesis } \\
\text { black }\end{array} \\
\end{array}$ & $\begin{array}{c}\text { Philotrypesis } \\
\text { yellow }\end{array}$ & $\begin{array}{l}\text { Watshamiella } \\
\text { long and short }\end{array}$ & Eukobelea \\
\hline Sympatric & Yes & No & No & Yes & Yes & No \\
\hline Dissimilarity Index & 0.324 & 0.024 & 0.072 & 0.190 & 0.327 & 0.005 \\
\hline Minimum model & ov $\sim$ tib*spp & ov $\sim$ tib & $\mathrm{ov} \sim \mathrm{tib}+\mathrm{spp}$ & $\mathrm{ov} \sim \mathrm{tib}+\mathrm{spp}$ & $\mathrm{ov} \sim \mathrm{tib}+\mathrm{spp}$ & ov $\sim$ tib \\
\hline P-value & $<2 \mathrm{e}-16$ & $1.42 \mathrm{e}-09$ & $1.395 \mathrm{e}-12$ & $<2 \mathrm{e}-16$ & $<2 \mathrm{e}-16$ & $7.48 \mathrm{e}-11$ \\
\hline Adjusted $\mathbf{R}^{2}$ & $\mathrm{R}^{2}=0.944$ & $\mathrm{R}^{2}=0.520$ & $\mathrm{R}^{2}=0.848$ & $\mathrm{R}^{2}=0.928$ & $\mathrm{R}^{2}=0.955$ & $\mathrm{R}^{2}=0.668$ \\
\hline F-statistic & $\mathrm{F}_{3,83}=482.6$ & $F_{1,49}=55.25$ & $\mathrm{~F}_{2,28}=84.39$ & $\mathrm{~F}_{2,76}=553.2$ & $\mathrm{~F}_{2,70}=781.2$ & $F_{1,38}=79.51$ \\
\hline
\end{tabular}


481 Figure 1. ANCOVA plots for ovipositor - hind tibia allometries for six congeneric species pair comparisons (left-hand panel) and associated species abundance distribution maps plotted on top of overlaid species distribution models (ENMs) (right-hand panel). Figure 1a shows comparisons of Sycoscapter 'long' versus both 'short' species combined and figure 1b shows comparisons of both Sycoscapter 'short' species only; figures 1c and 1d show comparisons of Philotrypesis species pair colour morphs thought to be nocturnal (yellow) and diurnal (black) dispersers; figures 1e and 1f show comparisons of Watshamiella ('long' and 'short' ovipositor) and Eukobelea congeneric pairs. Individual ENMs for species pairs follow the same blue and orange colour species coding; thus, overlapping regions of potential sympatry are 

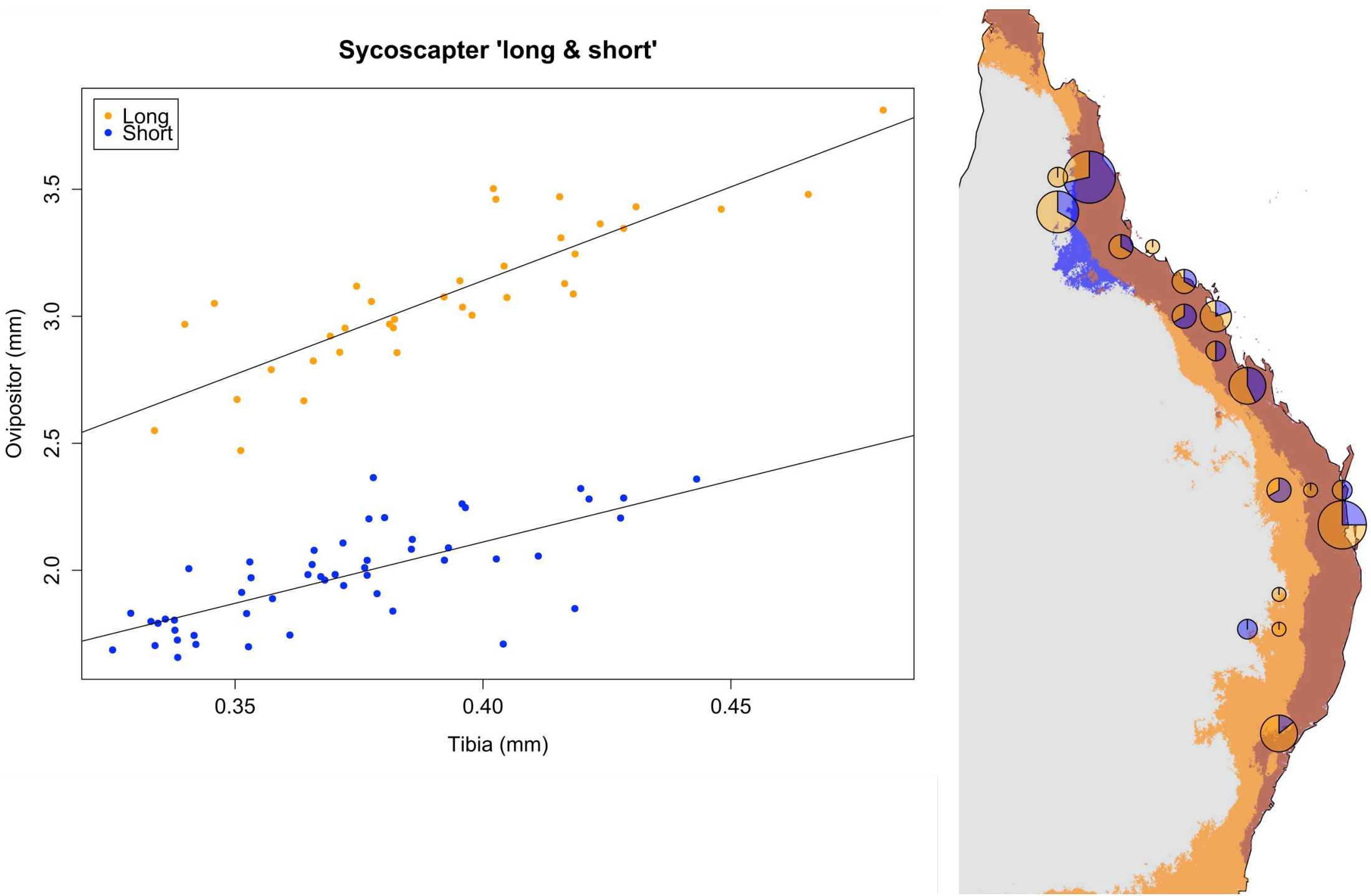

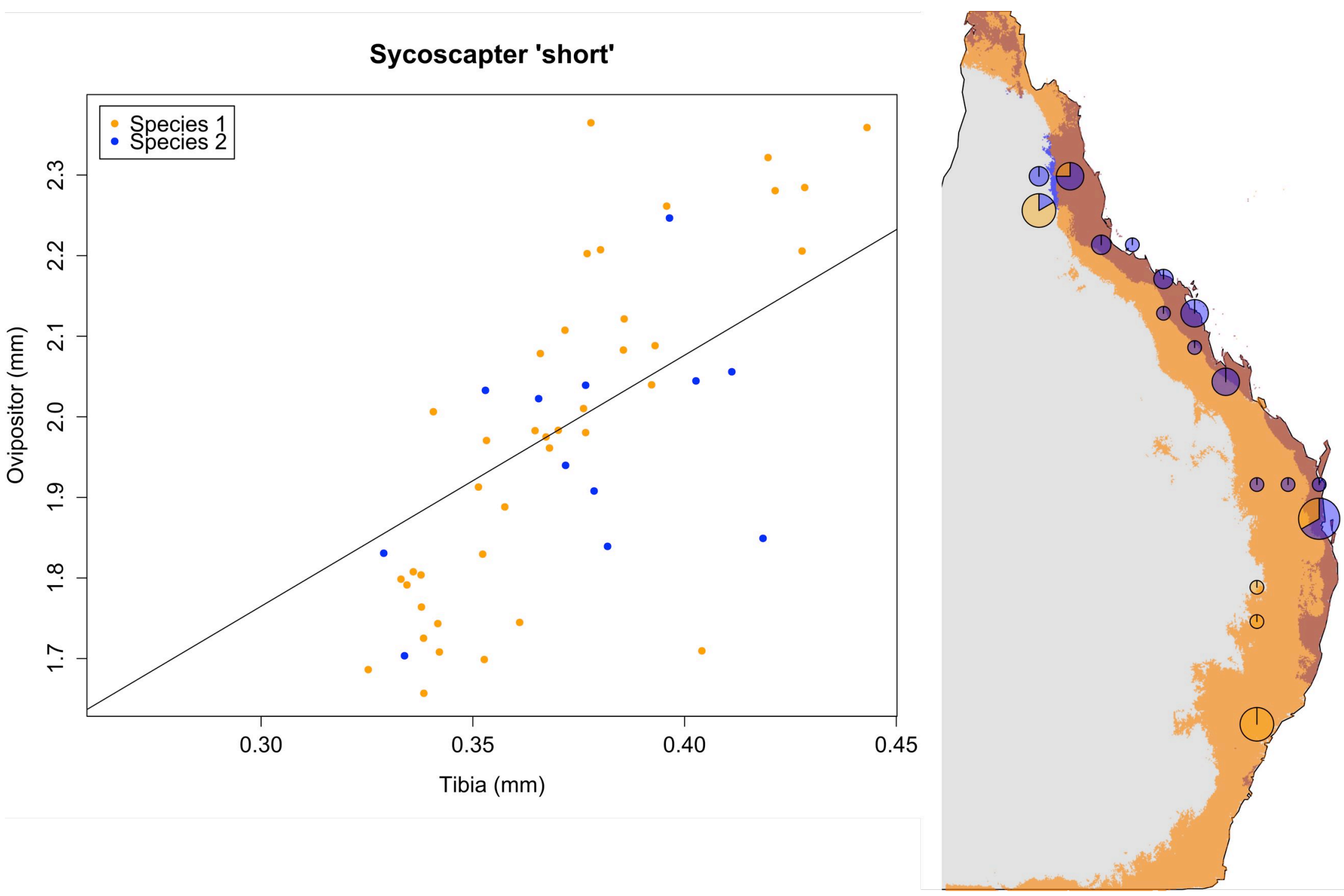


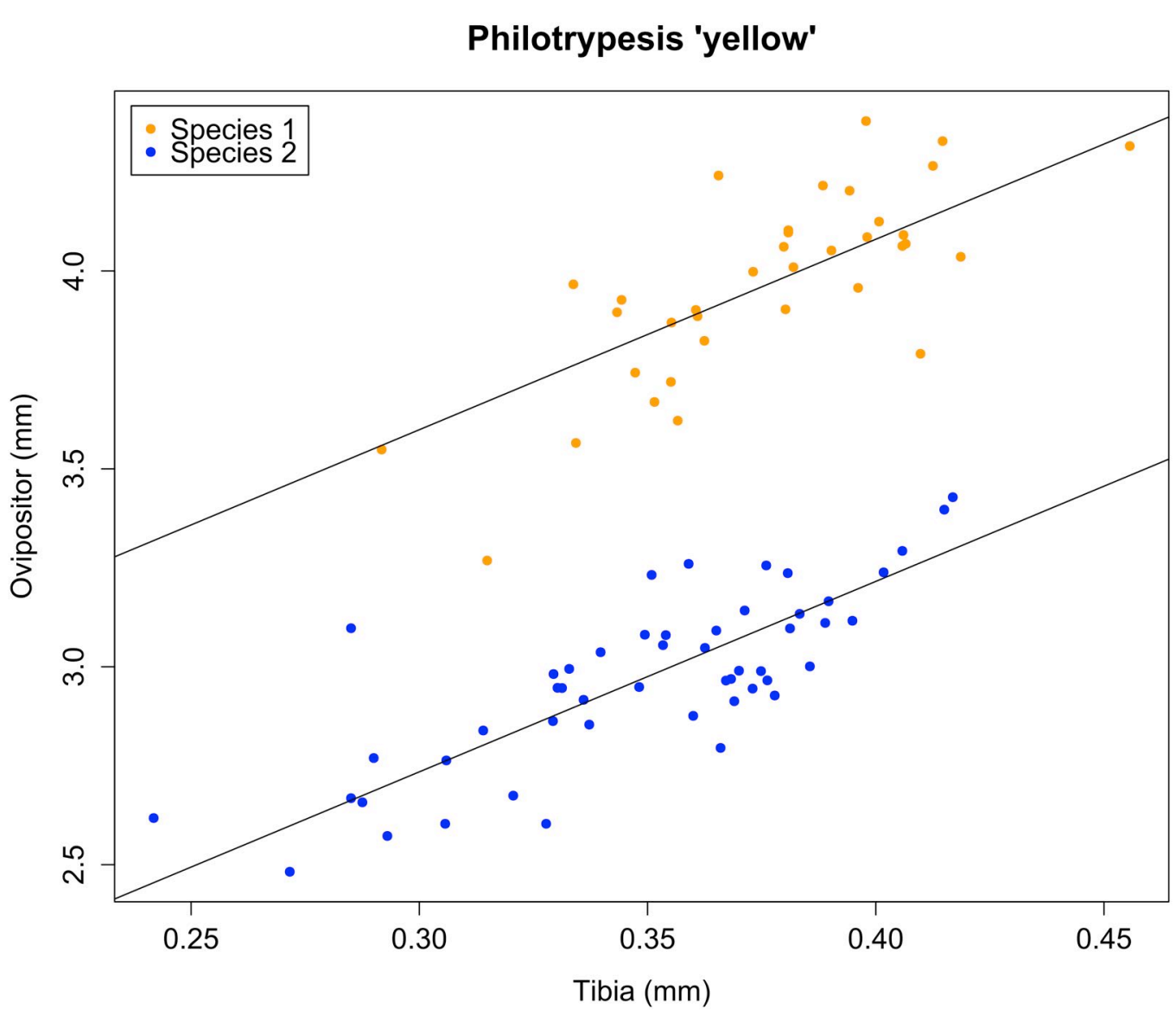


Philotrypesis 'black'

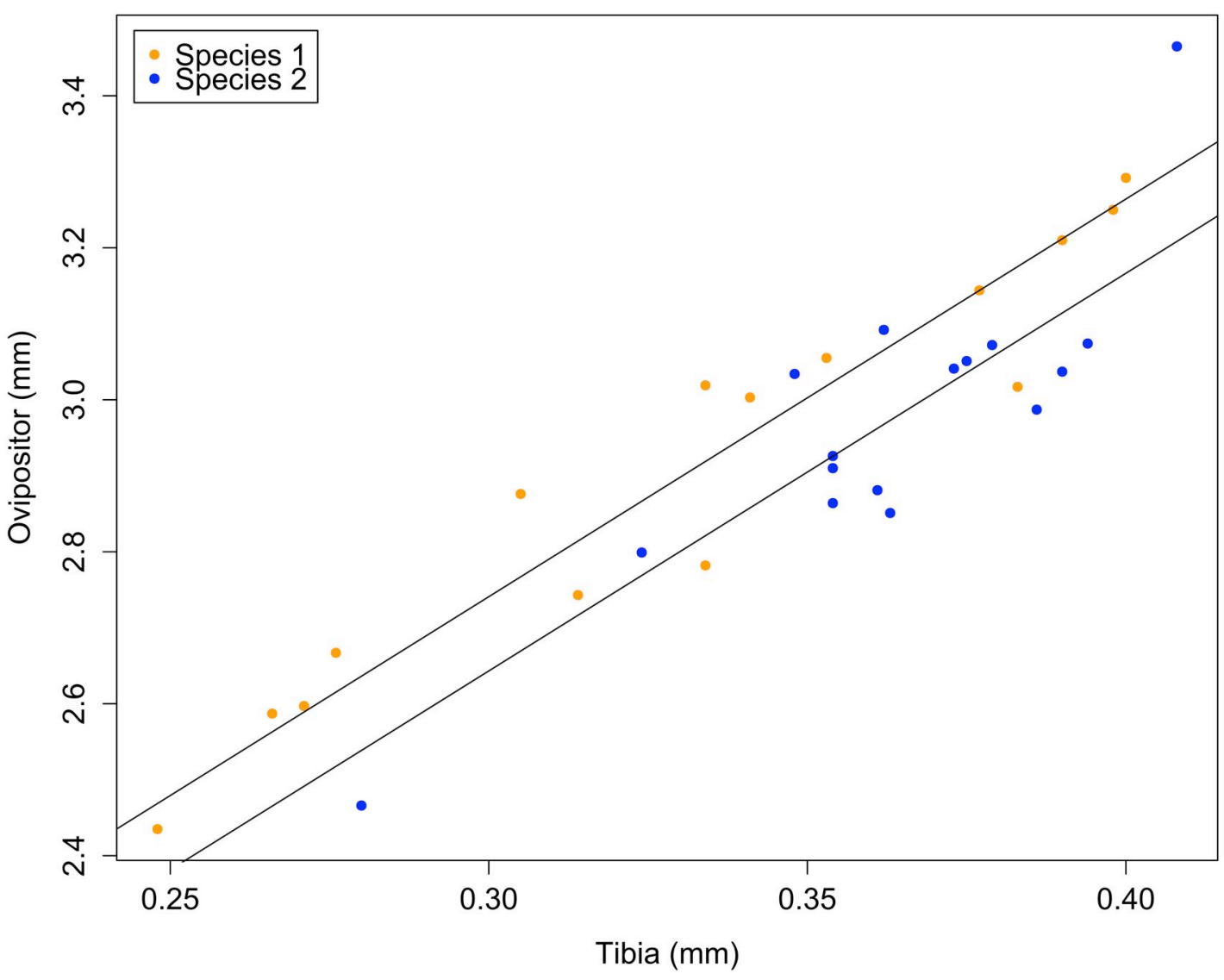

502

503

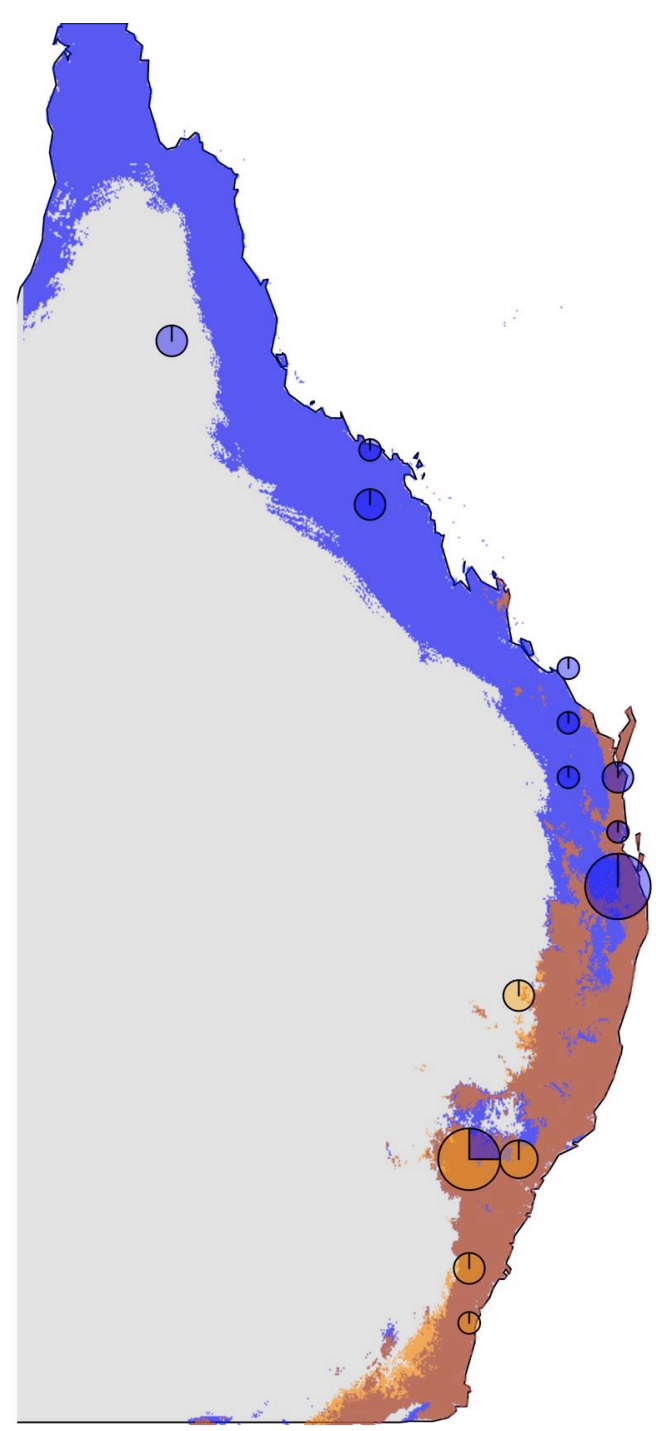



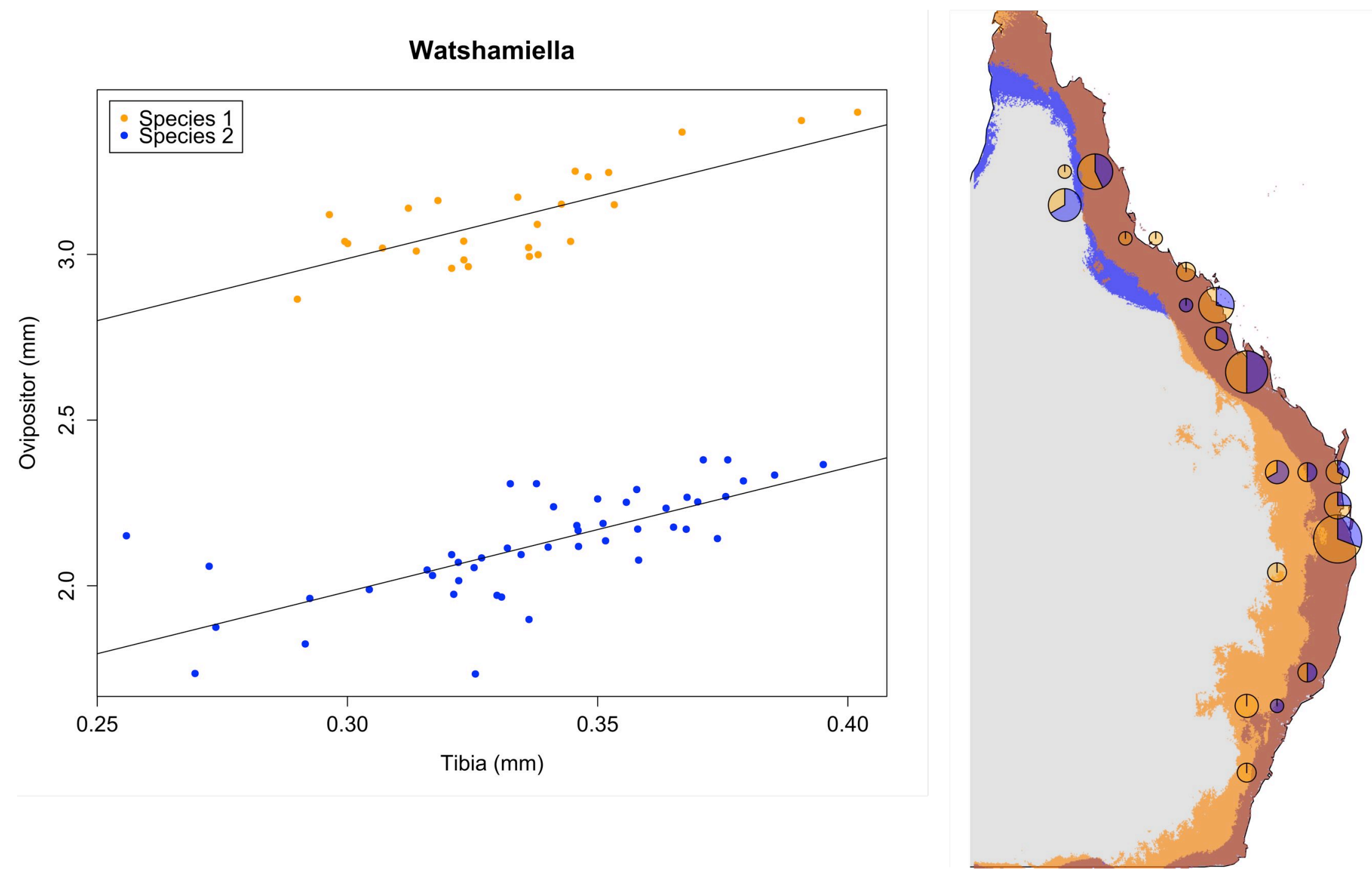


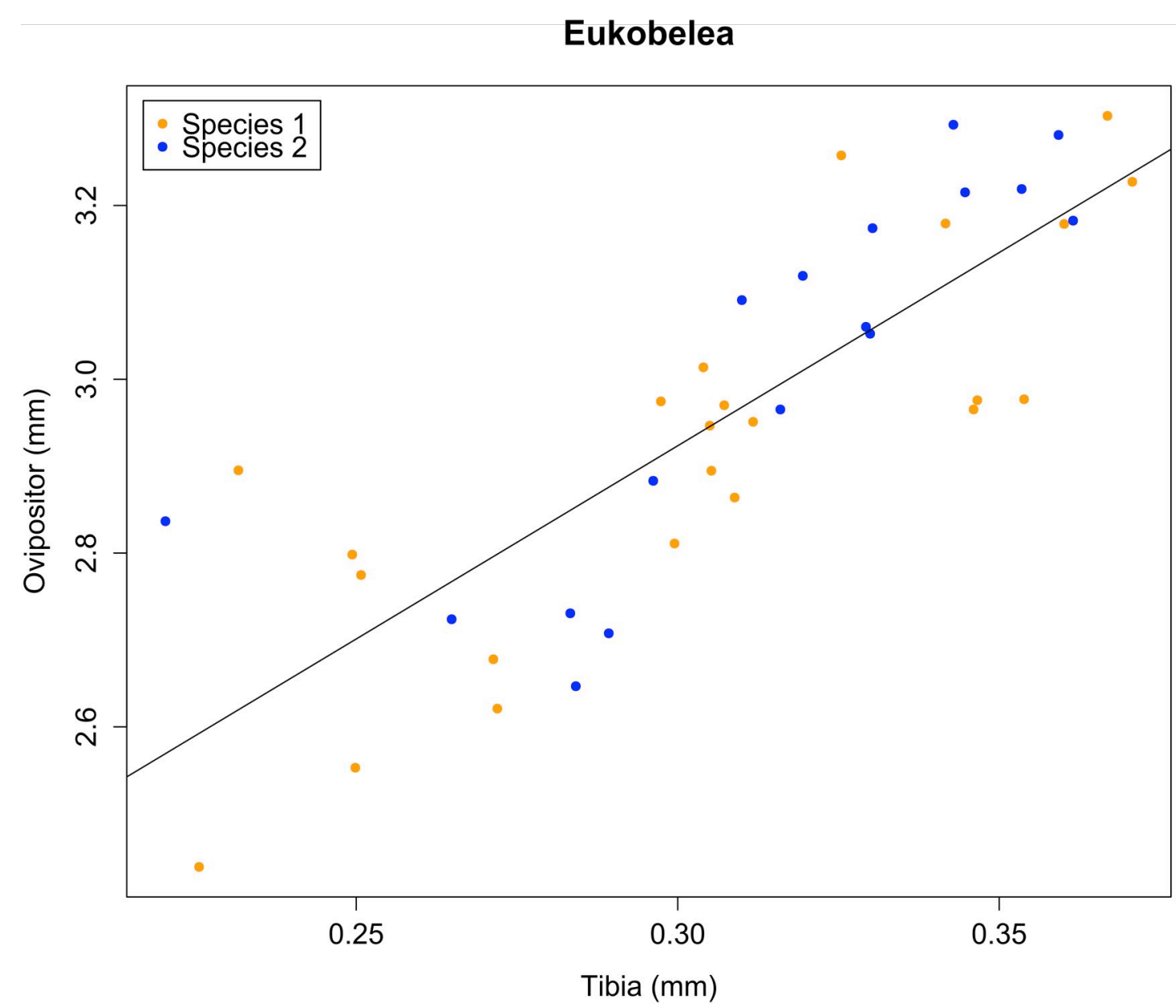


Acknowledgements: We would like to thank Ashley Montagu for assistance with DNA barcoding and David M. Althoff, Kari A. Segraves, Timothy Sutton and Brent Emerson for helpful comments regarding this manuscript. This work was funded by a NERC studentship (\#NE/G523912/1 - CTD) and NERC grant NE/J007986/1 (JMC).

\section{References}

Acs, Z., R. J. Challis, P. Bihari, M. Blaxter, A. Hayward, G. Melika, G. Csoka, Z. Penzes, J. PujadeVillar, J.-L. Nieves-Aldrey, K. Schoenrogge, and G. N. Stone. 2010. Phylogeny and DNA barcoding of inquiline oak gallwasps (Hymenoptera: Cynipidae) of the Western Palaearctic. Molecular Phylogenetics and Evolution 55:210-225.

al-Beidh, S., D. W. Dunn, S. A. Power, and J. M. Cook. 2012. Parasites and mutualism function: measuring enemy-free space in a fig-pollinator symbiosis. Oikos 121:1833-1839.

Anderson, R. P., A. T. Peterson, and M. Gomez-Laverde. 2002. Using niche-based GIS modeling to test geographic predictions of competitive exclusion and competitive release in South American pocket mice. Oikos 98:3-16.

Anderson, R. P., and A. Raza. 2010. The effect of the extent of the study region on GIS models of species geographic distributions and estimates of niche evolution: preliminary tests with montane rodents (genus Nephelomys) in Venezuela. Journal of Biogeography 37:1378-1393.

Blaxter, M. 2003. Molecular systematics - Counting angels with DNA. Nature 421:122-124.

Boria, R. A., L. E. Olson, S. M. Goodman, and R. P. Anderson. 2014. Spatial filtering to reduce sampling bias can improve the performance of ecological niche models. Ecological Modelling 275:73-77.

Bouteiller-Reuter, C., M. L. Hale, and J. M. Cook. 2009. Characterization of microsatellite markers for Sycoscapter nonpollinating fig wasps. Molecular Ecology Resources 9:832-835.

Calenge, C. 2006. The package "adehabitat" for the R software: A tool for the analysis of space and habitat use by animals. Ecological Modelling 197:516-519.

Chase, J. M., and M. A. Leibold. 2003. Ecological Niches: linking classical and contemporary approaches. University of Chicago Press, Chicago.

Chesson, P. 2000. Mechanisms of maintenance of species diversity. Annual Review of Ecology and Systematics 31:343-366.

Compton, S. G., S. van Noort, M. McLeish, M. Deeble, and V. Stone. 2009. Sneaky African fig wasps that oviposit through holes drilled by other species. African Natural History 5:9-15.

Cook, J. M., S. G. Compton, E. A. Herre, and S. A. West. 1997. Alternative mating tactics and extreme male dimorphism in fig wasps. Proceedings of the Royal Society B-Biological Sciences 264:747754.

Cook, J. M., C. Reuter, J. C. Moore, and S. A. West. 2015. Fighting in fig wasps: do males avoid killing brothers or do they never meet them? Ecological Entomology 40:741-747.

Cook, J. M., and S. T. Segar. 2010. Speciation in fig wasps. Ecological Entomology 35:54-66.

Cook, J. M., and S. A. West. 2005. Figs and fig wasps. Current Biology 15:R978-R980.

Coyne, J. A., and H. A. Orr. 2004. Speciation. Sinauer Associates, Inc, Sunderland, MA.

Cristescu, M. E. 2014. From barcoding single individuals to metabarcoding biological communities: towards an integrative approach to the study of global biodiversity. Trends in Ecology \& Evolution 29:566-571.

Darwell, C. T. 2013. Species composition and patterns of diversity in fig wasp communities. PhD. University of Reading, Reading, UK. 
Darwell, C. T., S. al-Beidh, and J. M. Cook. 2014. Molecular species delimitation of a symbiotic figpollinating wasp species complex reveals extreme deviation from reciprocal partner specificity. Bmc Evolutionary Biology 14.

Darwell, C. T., K. A. Segraves, and D. M. Althoff. 2016. The role of abiotic and biotic factors in determining coexistence of multiple pollinators in the yucca-yucca moth mutualism. Ecography.

Dixon, D. J., B. R. Jackes, and L. M. Bielig. 2001. Figuring out the figs: The Ficus obliqua-Ficus rubiginosa complex (Moraceae : Urostigma sect. Malvanthera). Australian Systematic Botany 14:133-154.

Duffy, J. E., B. J. Cardinale, K. E. France, P. B. McIntyre, E. Thebault, and M. Loreau. 2007. The functional role of biodiversity in ecosystems: incorporating trophic complexity. Ecology Letters 10:522-538.

Edwards, D. L., and J. Melville. 2010. Phylogeographic analysis detects congruent biogeographic patterns between a woodland agamid and Australian wet tropics taxa despite disparate evolutionary trajectories. Journal of Biogeography 37:1543-1556.

Eldredge, N., and J. Cracraft. 1980. Phylogenetic patterns and the evolutionary process method and theory in comparative biology.in N. Eldredge and J. Cracraft, editors. Phylogenetic Patterns and the Evolutionary Process: Method and Theory in Comparative Biology. Columbia University Press, New York, NY, USA.

Garcia-Robledo, C., E. K. Kuprewicz, C. L. Staines, T. L. Erwin, and W. J. Kress. 2016. Limited tolerance by insects to high temperatures across tropical elevational gradients and the implications of global warming for extinction. Proceedings of the National Academy of Sciences of the United States of America 113:680-685.

Graham, C. H., and P. V. A. Fine. 2008. Phylogenetic beta diversity: linking ecological and evolutionary processes across space in time. Ecology Letters 11:1265-1277.

Gutierrez, E. E., R. A. Boria, and R. P. Anderson. 2014. Can biotic interactions cause allopatry? Niche models, competition, and distributions of South American mouse opossums. Ecography 37:741753.

Haine, E. R., J. Martin, and J. M. Cook. 2006. Deep mtDNA divergences indicate cryptic species in a figpollinating wasp. Bmc Evolutionary Biology 6.

Hall, T. A. 1999. BioEdit: a user friendly biological sequence alignment editor and analysis program for Windows95/98NT. Nucleic Acids Symposium 41:95-98.

Harry, M., M. Solignac, and D. Lachaise. 1998. Molecular evidence for parallel evolution of adaptive syndromes in fig-breeding Lissocephala (Drosophilidae). Molecular Phylogenetics and Evolution 9:542-551.

Hawkins, B. A., and S. G. Compton. 1992. AFRICAN FIG WASP COMMUNITIES UNDERSATURATION AND LATITUDINAL GRADIENTS IN SPECIES RICHNESS. Journal of Animal Ecology 61:361-372.

Hebert, P. D. N., A. Cywinska, S. L. Ball, and J. R. DeWaard. 2003. Biological identifications through DNA barcodes. Proceedings of the Royal Society B-Biological Sciences 270:313-321.

Hebert, P. D. N., and T. R. Gregory. 2005. The promise of DNA barcoding for taxonomy. Systematic Biology 54:852-859.

Hebert, P. D. N., E. H. Penton, J. M. Burns, D. H. Janzen, and W. Hallwachs. 2004. Ten species in one: DNA barcoding reveals cryptic species in the neotropical skipper butterfly Astraptes fulgerator. Proceedings of the National Academy of Sciences of the United States of America 101:1481214817.

Hijmans, R. J., S. E. Cameron, J. L. Parra, P. G. Jones, and A. Jarvis. 2005. Very high resolution interpolated climate surfaces for global land areas. International Journal of Climatology 25:19651978.

Hubbell, S. P. 2001. The Unified Neutral Theory of Biodiversity and Biogeography (Monographs in Population Biology). Princeton University, Princeton, NJ, USA. 
Jermiin, L. S., and R. H. Crozier. 1994. THE CYTOCHROME-B REGION IN THE MITOCHONDRIAL-DNA OF THE ANT TETRAPONERA-RUFONIGER - SEQUENCE DIVERGENCE IN HYMENOPTERA MAY BE ASSOCIATED WITH NUCLEOTIDE CONTENT. Journal of Molecular Evolution 38:282-294.

Jones, M., A. Ghoorah, and M. Blaxter. 2011. jMOTU and Taxonerator: Turning DNA Barcode Sequences into Annotated Operational Taxonomic Units. Plos One 6.

Joseph, L., and C. Moritz. 1994. MITOCHONDRIAL-DNA PHYLOGEOGRAPHY OF BIRDS IN EASTERN AUSTRALIAN RAIN-FORESTS - FIRST FRAGMENTS. Australian Journal of Zoology 42:385-403.

Kerdelhue, C., J. P. Rossi, and J. Y. Rasplus. 2000. Comparative community ecology studies on old world figs and fig wasps. Ecology 81:2832-2849.

Kimura, M. 1980. A SIMPLE METHOD FOR ESTIMATING EVOLUTIONARY RATES OF BASE SUBSTITUTIONS THROUGH COMPARATIVE STUDIES OF NUCLEOTIDE-SEQUENCES. Journal of Molecular Evolution 16:111-120.

Kress, W. J., C. Garcia-Robledo, M. Uriarte, and D. L. Erickson. 2015. DNA barcodes for ecology, evolution, and conservation. Trends in Ecology \& Evolution 30:25-35.

Li, Y., X. Zhou, G. Feng, H. Hu, L. Niu, P. D. N. Hebert, and D. Huang. 2010. COI and ITS2 sequences delimit species, reveal cryptic taxa and host specificity of fig-associated Sycophila (Hymenoptera, Eurytomidae). Molecular Ecology Resources 10:31-40.

Macarthur, R., and R. Levins. 1967. LIMITING SIMILARITY CONVERGENCE AND DIVERGENCE OF COEXISTING SPECIES. American Naturalist 101:377-+.

Matthews, T. J., and R. J. Whittaker. 2014. Neutral theory and the species abundance distribution: recent developments and prospects for unifying niche and neutral perspectives. Ecology and Evolution 4:2263-2277.

May, R. M. 1973. Stability and Complexity in Model Systems. Princeton University Press, Princeton, NJ, USA.

May, R. M. 1990. HOW MANY SPECIES. Philosophical Transactions of the Royal Society of London Series B-Biological Sciences 330:293-304.

McLeish, M. J., and S. van Noort. 2012. Codivergence and multiple host species use by fig wasp populations of the Ficus pollination mutualism. Bmc Evolutionary Biology 12.

McLeish, M. J., S. Van Noort, and K. A. Tolley. 2010. Parasitoid fig-wasp evolutionary diversification and variation in ecological opportunity. Molecular Ecology 19:1483-1496.

Molbo, D., C. A. Machado, J. G. Sevenster, L. Keller, and E. A. Herre. 2003. Cryptic species of figpollinating wasps: Implications for the evolution of the fig-wasp mutualism, sex allocation, and precision of adaptation. Proceedings of the National Academy of Sciences of the United States of America 100:5867-5872.

Montero-Pau, J., and M. Serra. 2011. Life-Cycle Switching and Coexistence of Species with No Niche Differentiation. Plos One 6.

Muscarella, R., P. J. Galante, M. Soley-Guardia, R. A. Boria, J. M. Kass, M. Uriarte, R. P. Anderson, and J. McPherson. 2014. ENMeval: An R package for conducting spatially independent evaluations and estimating optimal model complexity forMaxentecological niche models. Methods in Ecology and Evolution 5:1198-1205.

Paine, R. T. 2002. Trophic control of production in a rocky intertidal community. Science 296:736-739.

Phillips, S. J., R. P. Anderson, and R. E. Schapire. 2006. Maximum entropy modeling of species geographic distributions. Ecological Modelling 190:231-259.

Phillips, S. J., and M. Dudik. 2008. Modeling of species distrbutions with Maxent: new extensions and a comprehensive evaluation. Ecography 31:161-175.

Pigot, A. L., J. A. Tobias, and W. Jetz. 2016. Energetic Constraints on Species Coexistence in Birds. Plos Biology 14:e1002407.

Price, P. W. 1980. Evolutionary biology of parasites. Princeton University Press, Princetone, NJ. 
Proffit, M., B. Schatz, R. M. Borges, and M. Hossaert-Mckey. 2007. Chemical mediation and niche partitioning in non-pollinating fig-wasp communities. Journal of Animal Ecology 76:296-303.

Puniamoorthy, N., M. A. Schaefer, and W. U. Blanckenhorn. 2012. SEXUAL SELECTION ACCOUNTS FOR THE GEOGRAPHIC REVERSAL OF SEXUAL SIZE DIMORPHISM IN THE DUNG FLY, SEPSIS PUNCTUM (DIPTERA: SEPSIDAE). Evolution 66:2117-2126.

Rasplus, J. Y., C. Kerdelhue, I. Le Clainche, and G. Mondor. 1998. Molecular phylogeny of fig wasps Agaonidae are not monophyletic. Comptes Rendus De L Academie Des Sciences Serie IiiSciences De La Vie-Life Sciences 321:517-527.

Ronquist, F., and J. P. Huelsenbeck. 2003. MrBayes 3: Bayesian phylogenetic inference under mixed models. Bioinformatics 19:1572-1574.

Rooney, N., and K. S. McCann. 2012. Integrating food web diversity, structure and stability. Trends in Ecology \& Evolution 27:40-46.

Schiffer, M., M. E. Carew, and A. A. Hoffmann. 2004. Molecular, morphological and behavioural data reveal the presence of a cryptic species in the widely studied Drosophila serrata species complex. Journal of Evolutionary Biology 17:430-442.

Segar, S. T., D. W. Dunn, C. T. Darwell, and J. M. Cook. 2014. How to be a fig wasp, down under: The diversity and structure of an Australian fig wasp community. Acta Oecologica-International Journal of Ecology 57:17-27.

Segar, S. T., R. A. S. Pereira, S. G. Compton, and J. M. Cook. 2013. Convergent structure of multitrophic communities over three continents. Ecology Letters 16:1436-1445.

Smith, M. A., E. S. Eveleigh, K. S. McCann, M. T. Merilo, P. C. McCarthy, and K. I. Van Rooyen. 2011. Barcoding a Quantified Food Web: Crypsis, Concepts, Ecology and Hypotheses. Plos One 6.

Smith, M. A., D. M. Wood, D. H. Janzen, W. Hallwachs, and P. D. N. Hebert. 2007. DNA barcodes affirm that 16 species of apparently generalist tropical parasitoid flies (Diptera, Tachinidae) are not all generalists. Proceedings of the National Academy of Sciences of the United States of America 104:4967-4972.

Sutton, T. L., M. Riegler, and J. M. Cook. 2016. One step ahead: a parasitoid disperses farther and forms a wider geographic population than its fig wasp host. Molecular Ecology 25:882-894.

Swofford, D. L. 2002. PAUP* Phylogenetic Analysis Using Parsimony (*and Other Methods).

Team, R. C. 2015. R: A Language and Environment for Statistical Computing. R Foundation for Statistical Computing.

Tzeng, H.-Y., L.-J. Tseng, C.-H. Ou, K.-C. Lu, F.-Y. Lu, and L.-S. Chou. 2008. Confirmation of the parasitoid feeding habit in Sycoscapter, and their impact on pollinator abundance in Ficus formosana. Symbiosis 45:129-134.

van Heerwaarden, B., V. Kellermann, M. Schiffer, M. Blacket, C. M. Sgro, and A. A. Hoffmann. 2009. Testing evolutionary hypotheses about species borders: patterns of genetic variation towards the southern borders of two rainforest Drosophila and a related habitat generalist. Proceedings of the Royal Society B-Biological Sciences 276:1517-1526.

Voda, R., L. Dapporto, V. Dinca, and R. Vila. 2015. Cryptic matters: overlooked species generate most butterfly beta-diversity. Ecography 38:405-409.

Warren, M., M. P. Robertson, and J. M. Greeff. 2010. A comparative approach to understanding factors limiting abundance patterns and distributions in a fig tree-fig wasp mutualism. Ecography 33:148-158.

Weiblen, G. D., and G. L. Bush. 2002. Speciation in fig pollinators and parasites. Molecular Ecology 11:1573-1578.

Wellborn, G. A., and R. D. Cothran. 2004. Phenotypic similarity and differentiation among sympatric cryptic species in a freshwater amphipod species complex. Freshwater Biology 49:1-13.

West, S. A., J. M. Cook, J. H. Werren, and H. C. J. Godfray. 1998. Wolbachia in two insect hostparasitoid communities. Molecular Ecology 7:1457-1465. 
White, T., T. Bruns, S. Lee, and J. Taylor. 1990. Amplification and direct sequencing of fungal ribosomal genes for phylogenies. PCR Protocols: A guide to methods and applications. Academic Press, Ney York, NY.

Whittaker, R. H. 1972. Evolution and measurement of species diversity. Taxon 21:213-251.

Xiao, J.-H., N.-X. Wang, Y.-W. Li, R. W. Murphy, D.-G. Wan, L.-M. Niu, H.-Y. Hu, Y.-G. Fu, and D.W. Huang. 2010. Molecular Approaches to Identify Cryptic Species and Polymorphic Species within a Complex Community of Fig Wasps. Plos One 5.

Zhai, S. W., D. R. Yang, and Y. Q. Peng. 2008. Reproductive strategies of two Philotrypesis species on Ficus hispida. Symbiosis 45:117-120.

Zhou, M.-J., J.-H. Xiao, S.-N. Bian, Y.-W. Li, L.-M. Niu, H.-Y. Hu, W.-S. Wu, R. W. Murphy, and D.W. Huang. 2012. Molecular approaches identify known species, reveal cryptic species and verify host specificity of Chinese Philotrypesis (Hymenoptera: Pteromalidae). Molecular Ecology Resources 12:598-606.

Data accessibility: We confirm that, should the manuscript be accepted, the data supporting the results will be archived in an appropriate public repository such as Dryad or Figshare and the data DOI will be included at the end of the article. Sequence data will be archived on Genbank.

Statement of authorship: CTD and JMC both designed the study and conducted field collections. CTD wrote the first draft of the manuscript, and all authors contributed substantially to revisions. CTD performed all taxonomic, morphological and molecular lab work, morphometric and statistical analyses, and molecular species delimitation. 